\title{
IT Alignment in the 3PL Industry: A Comparative Study
}

\author{
Kwok Hung Lau \\ School of Business IT and Logistics, RMIT University \\ Level 17, 239 Bourke Street, Melbourne 3000, Australia \\ charles.laudrmit.edu.au
}

\begin{abstract}
This research article reports the findings of a survey-based comparative study on current IT utilization by 3PL firms in the United States (US) and the People's Republic of China (PRC). The findings reveal that in general the level of IT utilization and IT focus of 3PL firms in the PRC are lower than that of their counterparts in the US. This may result in a bigger gap between customer expectations and experiences relating to IT capabilities of 3PL firms as observed in the Annual 3PL Studies. The gap may due to a misalignment in IT strategy and infrastructure between the 3PL firms and their customers. The contribution of this study is that, through the comparative analysis, it reveals the possible causes of the continuing IT capability expectation/performance gap as disclosed by the annual global 3PL studies and points to a potential solution to narrow the gap.
\end{abstract}

Keywords: IT utilization, IT focus, IT alignment model, Supply chain management, Outsourcing, Third-party logistics industry.

\section{Introduction}

Efficiency and responsiveness can be regarded as the primary goals in supply chain management [7]. To achieve these two objectives, effective communication and realtime information sharing are the keys. Information technology (IT) therefore plays a vital role in managing modern-day complex supply chains. It permits effective coordination of day-to-day replenishment and distribution activities hence minimizes delay and waste. It also provides visibility to enable tracing and tracking of inventory items thereby allows better control and greater flexibility in matching supply and demand. In addition, the technology enables internal as well as external integration. It helps promote collaboration among business partners through collective decision making using real-time data and information stored and shared on a common platform. Together with automation employing data captured via technologies such as barcode, global positioning, and radio frequency identification, IT can significantly reduce labour, errors, and response time across the entire supply chain. This will not only lower total supply chain costs (i.e., higher efficiency) but also enhance overall customer service (i.e., improved responsiveness). In fact, the significance and benefits of IT in the logistics industry has long been recognized in many studies $[4,5]$. 


\subsection{IT for the Third-Party Logistics Industry}

Globalization and outsourcing have impacted significantly on modern-day supply chain management. The former has resulted in extended supply chains with global configurations and multiple entry and exit points. The latter has given rise to the prosperity of integrated logistics service providers who look after all the logistics activities in a supply chain for various customers. IT plays a significant role in these changes. It is used to link up business partners in a supply chain to facilitate communication, coordination and collaboration. For example, fast expansion of the Internet and rapid advancement of Web technologies in the last couple of decades have extended the use of Electronic Data Interchange (EDI) from large corporations to small and medium-sized enterprises (SMEs). Similarly, instead of relying on costly Enterprise Resource Planning (ERP) systems for integration, SMEs can now employ newer and less expensive technologies such as Web Services to integrate with business partners that operate with different internal systems [26, 29]. Radio Frequency IDentification (RFID) technology, which permits real-time tracking and automation, enables efficient order assortment of fast moving products and achieves seamless integration between supply chain stages [9].

With more and more organizations outsourcing their logistics activities to thirdparty logistics (3PL) firms, IT has become an important asset to 3PL firms to integrate their systems with those of their clients in order to take over the logistics function effectively. As a bridge connecting clients and other members in the supply chain, IT in 3PL firms plays a critical role in synchronizing and coordinating complex supply chain activities across logistics users and their customers [19]. However, the high investment cost of some sophisticated IT systems, such as ERP, and the lack of IT expertise have dampened the utilization of IT by 3PL firms [25]. This is particularly so for small logistics firms which are usually limited in resources.

\subsection{Objectives of the Study}

Comparative studies on IT utilization by 3PL firms in developed and developing countries are relatively limited. While there are studies on the use of IT in logistics and supply chain management, many of them looked at general benefits $[4,15]$, strategy formulation [6, 17], applications [8,28], and impacts on competitive advantage and firm performance $[19,29]$. To fill the gap in the literature, this study attempts to compare IT utilization in the 3PL industry using the US and the PRC as examples. Effort is also made to investigate the possible reasons for the IT expectation/performance gap identified in annual global 3PL studies. The findings may shed light on how the expectation/performance gap can be narrowed. Through a questionnaire survey, answers to the following research questions are sought:

RQ1 - What are the current levels of IT utilization in the 3PL industry of the US and the PRC?

RQ2 - What are the competitive advantages obtained from IT utilization as perceived by the 3PL firms?

RQ3 - What are the possible reasons for the expectation/performance gap in IT utilization? 


\section{Literature Review}

Third-party logistics is a booming industry. The latest findings from the 2009 14th Annual 3PL Study [20] show that expenditures on outsourcing as percentages of total logistics expenditures in the four regions under study, namely North America, Latin America, Asia-Pacific, and Europe, range from 47\% to 66\% in 2009 and are projected to increase to $54 \%$ to $74 \%$ by 2014 (p. 11). Many multinational corporations (MNC) seeking integrated logistics services tend to form alliances with large 3PL firms to simplify management and improve service quality [21]. In order to provide efficient and responsive service to clients, 3PL firms are investing in IT to improve communication, enhance visibility, and integrate with clients' information systems. Study has shown that "information technology is viewed as central to the overall performance and effectiveness of 3PL-customer relationship" [20] (p. 13). The advantages of using IT in supply chain management are many. At the operational level, it helps reduce costs and errors through enhanced visibility, improved coordination, and data-driven automation. The reduction in lead time and waste translates into cost savings and other values in terms of greater efficiency and better responsiveness. At a strategic level, IT permits real-time information sharing among business partners to enable collaborative planning and collective decision making. This fosters alliances and partnerships and increases competitiveness of the whole supply chain in the long run.

\subsection{IT Capability Expectation/Performance Gap}

While there continues to be significant opportunities for outsourcing IT-based services, the Annual 3PL Study from 2002 to 2009 also consistently find a gap of $45 \%$ on average between shipper expectations of 3PL IT-based services and their actual experiences with these services [20] (p. 14). In the 2009 Study (p. 25), the biggest recurring issue as reported by the 3PL users is the lack of integration among internal 3PL systems (55\% of respondents reported such an issue). This can mean a lack of global visibility of orders and shipment with the 3PL managed network leading to unnecessary costly errors and delays. Other issues include inadequate performance reports $(42 \%)$, lack of sufficient project management processes or trained personnel (38\%), inability to provide sufficient order/shipment/inventory visibility (38\%), and data not available in a timely fashion (30\%), etc. They are all related to the lack of integration among the 3PL internal systems or with the customer's systems to obtain and share accurate real-time information. The persisting expectation/performance gap not only suggests an urgency for 3PL firms to further invest in IT in order to meet the needs of their clients but also a need to understand why such a gap exists and how it can be narrowed in the long run.

\subsection{Resource-Based View and Network Theory}

The resource-based view [2,27], which sees a firm as a bundle of resources and assets and emphasizes the use of rare, valuable, in-imitable and un-substitutable resources to gain sustainable competitive advantage, can serve as the underpinning theory for IT utilization by firms in general. Wu et al. [29] (p. 494) contend that "IT can facilitate the development of higher-order organizational capabilities, namely supply chain 
capabilities, which are firm specific and hard to duplicate across organizations". It is the information advantage achieved through the adoption of sophisticated technologies and the synergistic benefits achieved through an integrated system that provide a firm with sustainable competitive advantage [3]. On the other hand, the network theory (NT), which contends that performance of a firm depends not only on how efficiently it cooperates with its direct partners but also how well these partners cooperate with their own business partners through exchange and mutual adaptation processes $[11,16]$, can be used to account for the significance of IT utilization by the 3PL firms. Study by Posey and Bari [24] suggests that the degree to which supply chain members' information systems are compatible with each other plays a significant role in information-processing capabilities. As an integrated service provider to many supply chain members, IT capability of the 3PL firm can determine the overall competitiveness and success or failure of a supply chain.

\subsection{A Proposed IT Alignment Model}

According to $\mathrm{Wu}$ et al. [29], supply chain capabilities encompass four dimensions: information exchange (which refers to a firm's ability to share knowledge with its supply chain partners), coordination (which refers to a firm's ability to coordinate transaction-related activities with supply chain partners), inter-firm activity integration (which refers to the extent to which a firm coordinates its strategic channel activities such as planning and forecasting with its supply chain partners), and supply chain responsiveness (which refers to the extent to which channel members respond cooperatively to environmental changes). Without investing in the appropriate IT, a 3PL firm will not be able to acquire these capabilities in order to operate and manage the logistics and supply chain activities of its clients effectively. Wu et al. [29] also propose that adoption of IT should focus on proper advancement and alignment. IT advancement refers to the extent to which a firm adopts the most sophisticated technology. For a 3PL service provider, proactive adoption and implementation of advanced IT to find solutions for customers ahead of competitors is crucial in gaining a competitive edge. IT alignment refers to the extent a firm's IT is compatible with that of its channel partners. For a 3PL firm, it is important that the IT systems it uses can integrate with those of its clients and their supply chain partners to enable information sharing and coordination. The IT capability gap as revealed in the Annual 3PL Study clearly reinforces the significance of these two considerations. To facilitate analysis, this study uses a framework adapted from the strategic alignment model developed by Henderson and Venkatraman [12]. Figure 1 depicts how IT advancement and alignment, both internal and external, can be achieved through strategic fit and functional integration. For example, if a 3PL firm decides to adopt a blue ocean strategy [18] to develop new markets to enjoy greater first-mover benefits, it would have to invest continuously in latest IT technologies and use them to provide more efficient and value-added services to its clients. Also, it would collaborate closely with its clients using IT to form long-term business partners to share risks and rewards. This would lead to mutual alignment of their respective IT systems in the long run to facilitate effective communication and information sharing for synchronization and optimization of various logistics processes [17]. While the capability building process as advocated in the RBV theory accounts for the internal IT advancement, external IT 


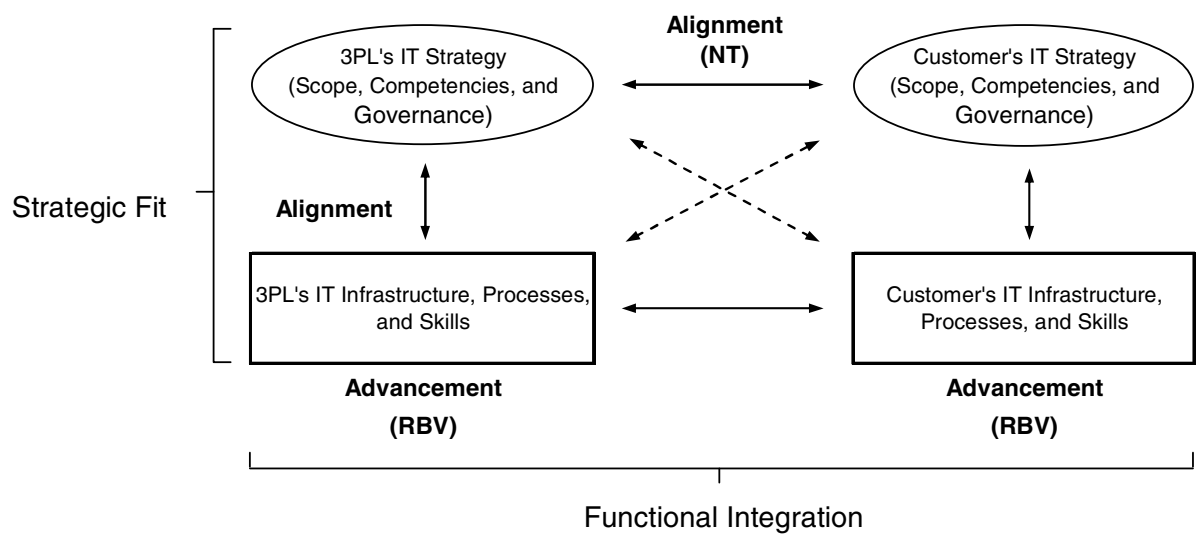

NOTE: The RBV theory accounts for internal IT advancement as a capability building process. The NT accounts for external alignment through exchange and mutual adaptation processes.

Source: Adapted from Henderson and Venkartraman [12]

Fig. 1. IT advancement and alignment between 3PL firm and its customer

alignment is made possible through the exchange and mutual adaptation processes as emphasized in the NT.

\section{Methodology}

This research used a self-administered questionnaire survey approach to collect data for analysis. A list of 3PL firms operating in the Yangtze Delta Region (YDR) of the PRC was compiled using the information obtained from the Ministry of Communications (MOS) of China. The choice of the YDR as a study area, which includes major cities such as Shanghai, Wuxi, Hangzhou, Suzhou, Kunshan, and Ningbo, is that it is the most fast developing economic region in China in recent years attracting a significant amount of foreign investment. YDR has now become one of the major manufacturing centres in China with a booming 3PL industry. 300 companies were randomly selected from the list for survey. For comparison, 300 3PL firms in the US were also randomly selected for survey from the member list of the Council of Supply Chain Management Professionals (CSCMP). Questionnaires were sent by e-mail to the selected companies obtained from the company websites. Follow-up telephone calls were made to solicit response and assist in the completion of the questionnaire where necessary. The survey was conducted and completed in May of 2009. A total of 75 valid responses, 36 from the US firms and 39 from the Chinese firms, were gathered with an overall response rate of $12.5 \%$ which is quite typical for self-administered questionnaire survey.

To facilitate response, close-ended questions are asked in the questionnaire. The questions are set on the basis of the literature review with reference to the Annual 3PL Studies in design. To encourage response, a relatively short questionnaire is employed. There are a total of 30 questions investigating the current level of IT 
utilization in the firm, the IT focus, and the competitive advantages brought to the company because of the use of IT. The first section (with 2 questions) collects background information of the company as to the size (in terms of number of employees) and years of operation in the industry. The second section (with 11 questions) investigates the current level of IT utilization. The areas of investigation are similar to those explored in the Annual 3PL Studies. Respondents were requested to use a 5-point Likert scale ranging from 1 (Very Low) to 5 (Very High) to measure the level of utilization. The third section (with 7 questions) investigates the current level of IT focus in the surveyed firm. The last section (with 10 questions) investigates the perceived competitive advantages that IT has brought to the firm. For questions in the last two sections, a 7-point Likert scale ranging from 1 (None) to 7 (All) is used to gauge the views. The self-evaluation approach has been adopted in many studies on supply chain and logistics performance $[22,23]$. Although there might be possibilities of under- or over-assessment of performance on certain activities by individual respondents, the aggregate findings should reflect more or less the current situation. The emphasis on relative rather than absolute performance using ranks in a comparative study will further lessen the impact of any random assessment bias. As the data are collected in ordinal scale, non-parametric tests were used in analysing the data.

\section{Findings and Discussion}

\subsection{Profile of the Companies Surveyed}

Among the 75 3PL companies surveyed, 10 are small companies (with 50 or less employees), 43 are medium-sized (with 51 to 250 employees), and 22 large companies (with more than 250 employees). The classification follows the EU practice [10]. Most of the surveyed companies are not new establishments. While the majority $(53 \%)$ has a history of establishment between 3 to 8 years, $44 \%$ of the companies have been in the business more than 8 years. The proportions of responding firms by firm size (in terms of number of employees) and years of operation in the two samples are not quite the same. Chi-square tests confirm that at $\alpha=0.05$ the proportions in the

Table 1. Profile of the companies surveyed

\begin{tabular}{lrrr}
\hline & US & PRC & Total \\
\hline Mailouts and Returns & & & \\
- Questionnaires sent & 300 & 300 & 600 \\
- Valid returns received & 36 & 39 & 75 \\
- Response rate & $12.0 \%$ & $13.0 \%$ & $12.5 \%$ \\
Number of Employees & & & \\
- Less than 50 & 0 & 10 & 10 \\
- 50 - 250 & 18 & 25 & 43 \\
- More than 250 & 18 & 4 & 22 \\
Years of Operation & & & \\
- Less than 3 years & 0 & 2 & 2 \\
- 3-8 years & 15 & 25 & 40 \\
- More than 8 years & 21 & 12 & 33 \\
\hline
\end{tabular}


two samples are different. The greater numbers of large and long established 3PL firms in the US sample may suggest that the development of the 3PL industry in the US is more mature.

\subsection{Current Level of IT Utilization}

Respondents were asked to gauge on a 5-point Likert scale their current level of IT utilization in 11 areas, which include visibility enhancement, Web-based communication, transport management, warehouse/DC management, etc. The results are summarized in Table 2. On the whole, the US 3PL firms are using IT to a greater extent in all areas when compared with their counterparts in the PRC. The MannWhitney $U$ test results confirm that the median values of the two samples in all the 11 aspects are significantly different. Nevertheless, it seems that the use of visibility tools (VT), Web-based communication technologies such as Web-based EDI (WEDI), transport management system (TMS), and warehouse management system (WMS) is relatively common in both cases. For the US firms, the use of collaborative tools, Internet-based transportation logistics exchange, supplier relationship management system, and customer order management system are also relatively extensive suggesting that the 3PL firms are also investing in integration and collaboration with supply chain partners using IT. While VT, WEDI, TMS, WMS are essential to the provision of logistics services, integration and collaboration tools are important to integrated logistics providers to provide total supply chain solutions to customers. The heavier usage of these tools by the 3PL firms in the US suggests a greater awareness of the significance of IT alignment with their clients as shown in the proposed IT advancement and alignment framework (Figure 1). The alignment can help reduce the expectation/performance gap in the long run. The tighter integration and collaboration may also help to increase the overall efficiency and responsiveness of the whole supply chain as advocated in the network theory.

Table 2. Current level of IT utilization by the 3PL firms surveyed

\begin{tabular}{lrrr}
\hline & $\begin{array}{r}\text { US }\left(N_{l}=36\right) \\
\text { Median }\end{array}$ & $\begin{array}{r}\text { PRC }\left(N_{2}=39\right) \\
\text { Median }\end{array}$ & $\begin{array}{r}\text { M-W U Test } \\
\text { Calculated } Z\end{array}$ \\
\hline IT Utilization & & 3 & -6.07 \\
- Visibility tools & 4 & 3 & -6.58 \\
- Web-enabled communication & 4 & 3 & -6.64 \\
- Transportation management & 4 & 3 & -6.08 \\
- Warehouse/DC management & 4 & $1 *$ & -6.81 \\
- RFID & 3 & 3 & -6.92 \\
- Internet-based transportation logistics & 4 & 3 & -6.94 \\
- exchange & 4 & 3 & -5.70 \\
- Supplier relationship management & & 3 & -5.90 \\
- Customer order management & 4 & 2 & -4.69 \\
- Suptomer relationship management & 4 & 3 & -5.53 \\
\hline
\end{tabular}

Scale: 1 = Very Low, 2 = Low, 3 = Mid-range, 4 = High, 5 = Very High

$* N_{2}=33$ as 6 respondents did not use RFID, $\alpha=.001$, Critical $Z=-3.09$ 
Another interesting observation is that in comparison with their 3PL firms in the PRC, the US firms are more willing to invest in RFID which is still a more expensive technology than barcode. In this regard, the Chinese 3PL firms are lagging far behind with six out of 39 firms (all are small and medium-sized firms) not using RFID at all. Nevertheless, as RFID is likely to become a major technology in supply chain management in the near future, the earlier a 3PL firm to adopt the technology the greater a competitive edge it can enjoy over its competitors. This observation suggests that 3PL firms in the US may have a greater awareness of the importance of IT advancement as shown in the proposed IT advancement and alignment framework (Figure 1). It may corroborate the resource-based view theory that the 3PL firms in the US are using RFID as a unique capability to achieve sustainable competitive advantage.

\subsection{Current Level of IT Focus}

Respondents were asked to gauge their current focus on IT in terms of budget, infrastructure and equipment (i.e., hardware and software), and personnel using a 7-point Likert scale. They were also requested to indicate the level of involvement of their IT managers in company-wide strategic planning activities in comparison with other functional mangers again on a 7-point Likert scale. The results are summarized in Table 3. It can be seen that the US firms are putting more focus on IT than their Chinese counterparts in all the surveyed aspects particularly in budget. The MannWhitney $U$ test results again confirm the difference. The findings suggest that 3PL firms in the US may have a greater awareness of the significance of IT for their business and are therefore more willing to invest. The greater involvement of their IT managers in strategy formulation for the company also suggest that a greater understanding of the significance of internal IT alignment and advancement as shown in the proposed framework (Figure 1). The same conclusion may apply to the 3PL firms in the PRC although, in comparison, their IT focus is not as strong as their counterparts in the US probably because of resource constraints and shorter history of establishment.

Table 3. Current level of IT focus of the 3PL firms surveyed

\begin{tabular}{lrrr}
\hline & $\begin{array}{r}\text { US }\left(N_{l}=36\right) \\
\text { Median }\end{array}$ & $\begin{array}{r}\text { PRC }\left(N_{2}=39\right) \\
\text { Median }\end{array}$ & $\begin{array}{r}\text { M-W } U \text { Test } \\
\text { Calculated } Z\end{array}$ \\
\hline Resources Invested in IT & & 4 & -6.14 \\
- Budget & 6 & 4 & -4.37 \\
- Infrastructure and equipment $\quad$ Personnel & 5 & 4 & -5.93 \\
Involvement in Company's Strategic & 5 & & \\
Planning Activities & & 5 & -6.89 \\
- IT manager & 6 & 4 & -5.41 \\
- Operation manager & 5 & 4 & -3.82 \\
- Human resources manager $\quad$ Finance manager & 5 & 4 & -5.08 \\
\hline
\end{tabular}

Scale: $1=$ None, $2=$ Very little, $3=$ Little, $4=$ Average when compared with others, $5=$ Much, $6=$ Very much, $7=$ All $\alpha=.001$, Critical $Z=-3.09$ 


\subsection{Perceived Competitive Advantages}

To find out what competitive advantages IT has brought to the 3PL firms, all the surveyed companies were asked to gauge the different advantages they perceived on a 7-point Likert scale. 10 different advantages were investigated which can be grouped into three main categories in terms of cost, service variety, and service quality. As shown in Table 4, again the US firms are reporting greater perceived advantages than their Chinese counterparts in all aspects as confirmed by the results of the MannWhitney $U$ tests. An interesting observation is that in comparison with the 3PL firms in the PRC, 3PL firms in the US tend to be more eager to pass the cost benefits brought by IT to their clients in terms of lower service charge - an example of mutual benefits through shared risks and rewards. This can lead to stronger alliance and closer relationship with clients suggesting that 3PL firms in the US may be focusing more on long-term benefits than short-term gains. The tighter integration and collaboration through IT alignment with customers may contribute to the cost advantage they enjoyed. This lends support to the use of the proposed IT advancement and alignment framework as a yardstick to measure the IT capability expectation/performance gap. The more extensive use of IT by the US firms obviously pays off in terms of greater service variety advantage they enjoyed over their Chinese counterparts. This is important to 3PL firms regardless of whether they are mere logistics service providers or total supply chain solution providers. As for service quality advantage, heavier investment in IT by the US firms definitely improves responsiveness, accuracy, and customer service level. This is particularly conspicuous in the speed of service delivery as information sharing and centralized processing using IT is vital to the

Table 4. Competitive advantages brought by IT utilization as perceived by the firms surveyed

\begin{tabular}{|c|c|c|c|}
\hline & $\begin{array}{r}\text { US }\left(N_{l}=36\right) \\
\text { Median } \\
\end{array}$ & $\begin{array}{r}\text { PRC }\left(N_{2}=39\right) \\
\text { Median } \\
\end{array}$ & $\begin{array}{l}\text { M-W U Test } \\
\text { Calculated } Z\end{array}$ \\
\hline \multicolumn{4}{|l|}{ Cost Advantage } \\
\hline - Lower operating cost & 6 & 5 & -6.46 \\
\hline - Lower service charge to customers & 6 & 4 & -5.80 \\
\hline \multicolumn{4}{|l|}{ Service Variety Advantage } \\
\hline - More services available to customers & 6 & 4 & -5.66 \\
\hline - Customized services to customers & 5 & 4 & -5.77 \\
\hline \multicolumn{4}{|l|}{ Service Quality Advantage } \\
\hline - Faster delivery of service & 6.5 & 5 & -4.83 \\
\hline - More reliable delivery of service & 6 & 5 & -4.66 \\
\hline $\begin{array}{l}\text { - More accurate order management and } \\
\text { inventory control }\end{array}$ & 6 & 5 & -5.09 \\
\hline $\begin{array}{l}\text { - Quicker response to customer require- } \\
\text { ment }\end{array}$ & 6 & 5 & -4.05 \\
\hline $\begin{array}{l}\text { Faster follow-up with customer claims } \\
\text { and complaints }\end{array}$ & 6 & 5 & -3.76 \\
\hline $\begin{array}{l}\text { - Smoother communication with custom- } \\
\text { ers }\end{array}$ & 5 & 5 & -5.50 \\
\hline
\end{tabular}

Scale: $1=$ None, $2=$ Very little, $3=$ Little, $4=$ Average when compared with others, $5=$ Much, $6=$ Very much, $7=$ All $\quad \alpha=.001$, Critical $Z=-3.09$ 
coordination, synchronization, and optimization of logistics activities which can help remove all the unnecessary delay in the process to achieve seamless operation. Again, these observations support the use of the RBV, the NT, and the proposed IT advancement and alignment framework to understand the causes of the IT capability expectation/performance gap and develop solutions to reduce the disparity.

\section{Conclusions and Further Research}

Through a sampled questionnaire survey, this study has investigated the current IT utilization, focus, and perceived competitive advantages in the 3PL industry of the US and the PRC. The findings reveals that IT is being extensively utilized in the industry of both countries but the US firms are obviously investing more in IT as having a stronger IT focus. The findings also suggest that the US firms are more aware of the significance of external IT alignment with their customers as well as internal IT advancement. The greater use of collaboration tools and automatic data capture technology such as RFID manifests this awareness. It is believed that the emphasized IT investment and focus by the US firms is a capability building process which can help them achieve long-term competitive advantages as advocated by the resource-based theory $[2,27]$. Their external IT alignment can also be accounted for by the network theory $[11,16]$. In contrast, 3PL firms in the PRC tend to use IT more for the provision of routine logistics services instead of total integrated supply chain solution. The relatively lower investment in integration and collaboration tools and RFID may be due to the lack of resources as well as the shorter history of establishment. As a result, external IT alignment with customers and internal IT advancement may be limited. The lower IT investment brings relatively lower cost, service variety and quality advantages to the Chinese firms in comparison with their US counterparts. This suggests that without building IT as a unique capability, 3PL firms in the PRC may not be able to achieve greater long-term competitive advantage as predicted by the resourcebased theory. The slow progress in external IT alignment and internal IT advancement also means that the expectation/performance performance gap identified in the Annual 3PL Study would be likely to remain in the near future.

This study is a relatively simple survey using non-parametric statistical analysis to present a general picture of the current IT utilization in the 3PL industry of the US and the PRC for comparison purpose. Although it does have contributed to knowledge by providing a snapshot of the current situation as well as corroborating the theories with the findings, the relatively short questionnaire has prohibited the gathering of more in-depth information to explore the myriad factors affecting a firm's decision on IT investment. Also, the survey has focused only on the service providers. The perspective of the users has yet to be investigated particularly when measures to narrow the expectation/performance gap are to be explored. Future research may extend the survey to cover a larger sample and to include customers as well as other business partners in the supply chain so as to investigate the benefits of IT utilization across the whole supply chain. Another limitation is that cultural impact has not been duly controlled in this comparative study $[13,14]$. Although this study follows the practice of major 3PL surveys such as the Annual 3PL Study [20] and the World Bank's study on global logistics performance index [1] in which cultural influence is not considered a 
major factor in the comparative analyses, it would be desirable to take the cultural elements into account in future investigation.

Acknowledgments. The author would like to thank the companies and their employees surveyed in this study for providing the information. His sincere thanks also go to the three anonymous reviewers for offering their valuable comments and suggestions on improving the paper.

\section{References}

1. Arvis, J.-F., Mustra, M.A., Panzer, J., Ojala, L., Naula, T.: Connecting to Compete - Trade Logsitics in the Global Economy: The Logistics Performance Index and Its Indicators. The World Bank (2007), http: / /www . worldbank . org / lpi

2. Barney, J.B.: Firm resources and sustained competitive advantage. Journal of Management 17, 99-120 (1991)

3. Bharadwaj, A.S.: A resource-based perspective on information technology capability and firm performance: an empirical investigation. MIS Quarterly 24, 169-196 (2000)

4. Bowersox, D.J., Daugherty, P.J.: Logistics paradigms: the impact of information technology. Journal of Business Logistics 16, 65-80 (1995)

5. Bowersox, D.J., Closs, D.J., Stank, T.P.: 21st century logistics: making supply chain integration a reality. Supply Chain Management Review 3, 17-28 (1999)

6. Carr, N.: IT doesn't matter. Harvard Business Review 81, 41-49 (2003)

7. Chopra, S., Meindl, P.: Supply Chain Management: Strategy, Planning, and Operations. Pearson Prentice-Hall, New York (2010)

8. Davenport, T., Brooks, J.: Enterprise systems and the supply chain. Journal of Information Management 17, 8-19 (2004)

9. Deloitte: Chips with Everything. Deloitte, London (2003), http: / /www.rfid4u.nl/downloads/deloittechipwitheverything.pdf

10. European Commission: Enterprise and Industry - Small and medium sized enterprises (SMEs). European Commission (2003), http://ec.europa.eu/enterprise/ policies/sme/facts-figures-analysis/ sme-definition/index_en.htm

11. Haakansson, H., Ford, D.: How companies interact in business networks? Journal of Business Research 55, 133-139 (2002)

12. Henderson, J.C., Venkatraman, N.: Understanding strategic alignment. Business Quarterly 55, 72-79 (1991)

13. Hofstede, G.: Culture's Consequences - Comparing Values, Behaviors, Institutions and Organizations Across Nations. Thousand Oaks, London (2001)

14. House, R.J., Wright, N.S., Aditya, R.N.: Cross-cultural research on organizational leadership: measurement of cultural dimensions. In: Earley, P.C., Erez, M. (eds.) New Perspectives on International Industrial/Organizational Psychology, pp. 571-581. New Lexington Press, San Francisco (1997)

15. Introna, L.D.: The impact of information technology on logistics. International Journal of Physical Distribution and Logistics Management 21, 32-37 (1991)

16. Johanson, J., Mattsson, L.G.: Inter-organizational relations in industrial systems: a network approach compared with the transaction cost approach. Inter-Organizational Studies of Management and Organization 17, 34-48 (1987) 
17. Kim, C., Yang, K.H., Kim, J.: A strategy for third-party logistics systems: a case analysis using the blue ocean strategy. Omega 36, 522-534 (2008)

18. Kim, W.C., Mauborgne, R.: Blue ocean strategy: from theory to practice. California Management Review 47, 105-121 (2005)

19. Lai, F., Zhao, X., Wang, Q.: The impact of information technology on the competitive advantage of logistics firms in China. Industrial Management and Data Systems 106, 12491271 (2006)

20. Langley Jr., C.J., Albright, D., Morton, J., Wereldsma, D., Alf, M., Swaminathan, S., Smith, G., Murphy, J., Deakins, T.A., Hoemmken, S., Peters, K.: 2009 Third-Party Logistics: Results and Findings of the 14th Annual Study. Capgemini, Georgia Institute of Technology, Oracle (2009), http: / / www . 3plstudy. com

21. Lau, K.H., Ma, W.L.: A supplementary framework for evaluation of integrated logistics provider. International Journal of Information Systems and Supply Chain Management 1, 49-69 (2008)

22. Lin, C.Y., Ho, Y.H.: RFID technology adoption and supply chain performance: an empirical study in China's logistics industry. Supply Chain Management: An International Journal 14, 369-378 (2009)

23. McCormack, K., Ladeira, M.B., de Oliveira, M.P.V.: Supply chain maturity and performance in Brazil. Supply Chain Management: An International Journal 13, 272-282 (2008)

24. Posey, C., Bari, A.: Information sharing and supply chain performance: understanding complexity, compatibility, and processing. International Journal of Information Systems \& Supply Chain Management 2, 67-76 (2009)

25. Sum, C.C., Teo, C.B., Ng, K.K.: Strategic logistics management in Singapore. International Journal of Operations and Production Management 21, 1239-1260 (2001)

26. Vidgen, R., France, D., Powell, P., Woerndl, M.: Web service business transformation: collaborative commerce opportunities in SMEs. Journal of Enterprise Information Management 17, 372-381 (2004)

27. Wernerfelt, B.: A resource-based view of the firm. Strategic Management Journal 5, 171180 (1984)

28. White, A., Daniel, E.M., Mohdzain, M.: The role of emergent information technologies and systems in enabling supply chain agility. International Journal of Information Management 25, 396-410 (2005)

29. Wu, F., Yeniyurt, S., Kim, D., Cavusgil, T.: The impact of information technology on supply chain capabilities and firm performance: a resource-based view. Industrial Marketing Management 35, 1317-1323 (2006) 